\title{
ERRATUM
}

\section{Type III Secretion System Genes in Clinical Aeromonas Isolates}

M. R. Chacón, L. Soler, E. A. Groisman, J. Guarro, and M. J. Figueras

Departament de Ciències Mèdiques Bàsiques, Facultat de Medicina i Ciències de la Salut, Universitat Rovira $i$ Virgili, 43201 Reus, Spain, and Department of Molecular Microbiology, Howard Hughes Medical Institute, Washington University School of Medicine, St. Louis, Missouri 63110

Volume 42, no. 3, p. 1285-1287, 2004. Page 1287, column 1, line 26: “AY289105” should read “AY289195." 